\title{
Helminth metacommunity of small mammals in a Brazilian reserve: the contribution of environmental variables, host attributes and spatial variables in parasite species abundance
}

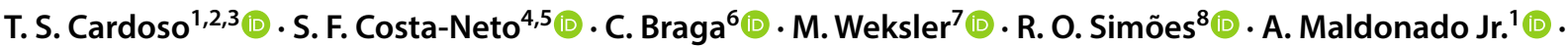 \\ J. L. Luque ${ }^{8} \cdot$ R. Gentile ${ }^{1}$ (D)
}

Received: 6 November 2019 / Accepted: 10 June 2020 / Published online: 20 June 2020

(c) The Author(s) 2020

\begin{abstract}
The role of environmental factors and landscape heterogeneity on species distribution on different spatial scales is one of the most important questions in community ecology. Variations in the environmental gradient characteristics, host attributes and spatial scales may influence the parasites distribution. The helminth metacommunity of 12 small mammal species was investigated in an Atlantic Forest reserve located in the State of Rio de Janeiro, southeast Brazil. We evaluated the influence of environmental variables, host attributes and spatial factors on the helminth metacommunity of small mammals, considering infracommunity and component community levels. Twenty-nine helminth morphospecies were recovered. The host attributes and spatial variables influenced the abundance of helminth species in the metacommunities for rodents and marsupials together, and for rodents alone at the infracommunity level. Host body mass, host diet and spatial variables at broad spatial scale (among localities) were the most important variables to explain the variation in helminth abundance. Parasite species richness influenced this variation only for the marsupial helminth metacommunity at the infracommunity level. The metacommunity showed larger turnover (parasite replacement) than nestedness (parasite loss) for their helminth species at both infracommunity and component community levels, which is associated with a high host specificity, and low helminth sharing among hosts for most species, resulting in a structured metacommunity.
\end{abstract}

Keywords Community structure $\cdot$ Ecology $\cdot$ Host-parasite interaction $\cdot$ Mechanistic approach $\cdot$ Parasitism

T. S. Cardoso

thiagoc@ioc.fiocruz.br

1 Laboratório de Biologia e Parasitologia de Mamíferos Silvestres Reservatórios, Instituto Oswaldo Cruz, Fundação Oswaldo Cruz, Av. Brasil 4365, Manguinhos, Rio de Janeiro, RJ 21045-900, Brazil

2 Programa de Pós-Graduação em Ciências Veterinárias, Universidade Federal Rural do Rio de Janeiro, Seropédica, RJ 23851-970, Brazil

3 Present Address: Programa Fiocruz de Fomento à Inovação-INOVA FIOCRUZ, Fundação Oswaldo Cruz, Av. Brasil 4365, Manguinhos, Rio de Janeiro, RJ 21045-900, Brazil

4 Fiocruz Mata Atlântica, Fundação Oswaldo Cruz, Jacarepaguá, Rio de Janeiro, RJ 22713-560, Brazil
5 Programa de Pós-Graduação em Biodiversidade e Saúde, Instituto Oswaldo Cruz, Fundação Oswaldo Cruz, Av. Brasil 4365, Manguinhos, Rio de Janeiro, RJ 21045-900, Brazil

6 Instituto de Biodiversidade e Sustentabilidade-NUPEM/UFRJ, Universidade Federal do Rio de Janeiro, Av. São José do Barreto 764, São José do Barreto, Macaé, RJ 27965-045, Brazil

7 Departamento de Vertebrados, seção de Mastozoologia, Museu Nacional, Universidade Federal do Rio de Janeiro, São Cristóvão, Rio de Janeiro, RJ 20940-040, Brazil

8 Departamento de Parasitologia Animal, Universidade Federal Rural do Rio de Janeiro, Seropédica, RJ 23851-970, Brazil 


\section{Introduction}

One of the greatest interests in community ecology is to understand how environmental factors and landscape heterogeneity can contribute to the species distribution in local communities considering different spatial scales (Peres-Neto and Legendre 2010). In this case, parasites may present nonrandom patterns of distribution in their hosts due to environmental factors. Variations in the spatial scale and in landscape characteristics may promote or limit parasite-host relationships along a certain environmental gradient (Richgels et al. 2013), considering both infracommunities (communities within a host individual) and component communities (communities including the entire local host population, i.e., all parasites found in the same host species) (Poulin 2007).

Metacommunities are local communities potentially linked by interactions among species (Leibold et al. 2004). They can be determined by the species diversity in each community and by the external factors related to species distribution and composition (Dallas and Presley 2014; Fernandes et al. 2014), where species composition represents which species is present or not in a given community, i.e., it can be interpreted as the presence or absence of species (Philippi et al. 1998). The analysis of metacommunities allows us to understand how organisms respond to ecological changes at different spatial scales (Winegardner et al. 2012; Braga et al. 2017). In host-parasite interactions, each host individual represents a dynamic community, the infracommunity, which interacts with the other communities in the environment, forming the component community (Combes 2001). The set of infracommunities or component communities, in turn, forms a metacommunity. In this case, environmental and spatial predictors, as well as factors related to the hosts themselves, can be determinant for the degree of similarity in the composition and abundance of parasite species among the communities that form a metacommunity (Dallas and Presley 2014; Heino et al. 2017). Although the metacommunity theory has emerged only in the last two decades, it has been applied in studies of host-parasite interaction of different taxa (Richgels et al. 2013; Nieto-Rabiela et al. 2018; Costa et al. 2019).

Measures comparing species diversity across communities, such as beta diversity (change in community composition between sites (Whittaker 1960), reflect distinct processes related to species replacement (spatial turnover) or loss (nestedness) across local and regional scales (Baselga 2010) and may be a result of environmental, spatial heterogeneity and/or historical factors. The decomposition of beta diversity in these two components, turnover and nestedness (Baselga 2010), allows a better understanding of the mechanisms associated with species distribution over a given metacommunity (Leibold and Mikkelson 2002; Presley et al. 2010). Recently, Baselga (2017) proposed an additive beta diversity model to decompose these two components taking into account species abundance. In this case, diversity between sites can be determined by a balanced variation in abundance or by the occurrence of abundance gradients, analogously to turnover and nestedness, respectively (Baselga 2017).

Studies that investigate the factors associated with the diversity of parasitic communities are fundamental for the understanding of host-parasite ecological interactions (Püttker et al. 2008; Simões et al. 2010; Dallas and Presley 2014; Cardoso et al. 2016; Castro et al. 2017). Ecological interactions between mammals and helminths have been previously investigated (Püttker et al. 2008; Simões et al. 2010; Cardoso et al. 2016; Castro et al. 2017), including analyses of metacommunity structure (Dallas and Presley 2014; Boullosa et al. 2019; Costa et al. 2019). Helminths form a very diverse group of parasites and infect several hosts worldwide, including humans, wild and domestic animals (Han et al. 2016). Helminths can also be used as biological indicators of environmental changes in different ecosystems (Vidal-Martínez and Wunderlich 2017).

The present study was part of a research project on biodiversity that aimed to investigate the fauna of several taxa in areas of the Atlantic Forest, including taxonomic, evolutionary, ecological, and parasitological aspects. Previous studies were developed with the helminth metacommunity of sigmodontine rodents in the same study area of the present study (Cardoso et al. 2018), and with the helminth metacommunity of the marsupial Didelphis aurita (Wied-Neuwied 1826), encompassing the localities of the present study and other areas (Costa-Neto et al. 2019). Both studies used the Elements of Metacommunity Structure analysis, without investigating the mechanisms responsible for the diversity structure observed. The former study indicated a random variation in the helminth species distribution, considering the species composition (Cardoso et al. 2018). The other study showed a checkerboard pattern for the infracommunities in the localities of the present study and quasi-nested and nested patterns, for component communities and infracommunities, respectively, in a regional scale including several localities (Costa-Neto et al. 2019).

Considering this, the objectives of this work were to investigate the mechanisms that influence the ecological structure of the helminth metacommunities of small mammals in a preserved area of Atlantic Forest in Brazil. The contribution of extrinsic environmental variables, host attributes and spatial variables in the abundance of the helminth species was investigated considering the entire small mammal community and within each host order (Didelphimorphia and Rodentia). We hypothesized that: 1-The 
helminth diversity varies among host species in response to (a) host attributes, (b) habitat variables of the environment, and (c) spatial variables as a function of the scale analyzed. This is expected because (a) host characteristics are determinant in host-parasite coevolution (Combes 2001); (b) the external environmental may influence the free-living stages of the helminths (Pakdeenarong et al. 2014), which can influence their distribution; and (c) the spatial heterogeneity increases with the distance (Soininen et al. 2007), resulting in different communities structures as we increase the spatial scale. 2-The helminth metacommunity is characterized by a larger turnover of parasite individuals and species among host species in comparison to the loss of parasite individuals along the helminth metacommunity. This may be due to the host-parasite coevolution and high host specificity found in most of the parasite species (Dallas and Presley 2014).

\section{Materials and methods}

\section{Study area}

The study was carried out in the Serra dos Órgãos National Park (PARNASO), municipality of Petrópolis, state of Rio de Janeiro, Southeastern Brazil, which represents a preserved forest area of 20,024 ha. This park is internationally recognized as a Biosphere Reserve and is one of the most important remnants of Atlantic Forest in Brazil. The municipality of Petrópolis covers $43 \%$ of the total area of PARNASO, which also comprises the municipalities of Teresópolis, Magé and Guapimirim (ICMBio 2018) (Fig. 1). The studied area is characterized by a Mountain Atlantic Forest of dense ombrophilous vegetation. The climate of this region is highland mesothermic ( $\mathrm{Cwb})$, according to the classification of Köppen, with mild temperatures, rainy summers and a dry season between June and August (Ayoade 1986).

The sampling of small mammals was carried out in three localities within PARNASO: Bonfim $\left(22^{\circ} 27^{\prime} 36,2^{\prime \prime} \mathrm{S} 43^{\circ}\right.$ 05 ' $37^{\prime \prime} \mathrm{W}, 1074 \mathrm{~m}$ ), Barragem do Caxambu (22 $30^{\circ} 20^{\prime}$ $\mathrm{S} 43^{\circ} 06^{\prime} 47,5^{\prime \prime} \mathrm{W}, 1117 \mathrm{~m}$ ), which had three linear transects each, and Uricanal ( $22^{\circ} 29^{\prime} 20.5^{\prime \prime} \mathrm{S} 43^{\circ} 07^{\prime} 27.8^{\prime \prime} \mathrm{W}$, $1056 \mathrm{~m}$ ), which had four linear transects (Fig. 1). Trappings occurred in late spring 2014 (rainy season) and winter 2015 (dry season).

\section{Sampling and collection of small mammals and helminths}

The captures were made in six linear transects composed of 15 capture stations equidistant in $20 \mathrm{~m}$, containing two traps each, one Tomahawk (Model 201, 16 in $\times 5$ in $\times 5$ inches, Wisconsin, USA) and one Sherman live trap (Model XLK, 3 in $\times 3.75$ in $\times 12$ in, Florida, USA). In addition, pitfall traps made with 60-liter buckets buried in the ground were also installed on four linear transects with 20 capture stations equidistant in 10 meters. Sherman and Tomahawk traps were baited with a mixture of peanut butter, banana, oats and bacon. Each sampling period lasted 10 consecutive days. Small mammals were euthanized and necropsied, and their bionic data were recorded. Specimens were identified by external and cranial morphology. Rodent specimens of the
Fig. 1 Map of the study area indicating the sampling localities and transects in the Serra dos Órgãos National Park (PARNASO), Petrópolis, state of Rio de Janeiro, Brazil. Circles indicate transects in each locality: Bonfim (black circles), Uricanal (gray circles) and Barragem do Caxambu (white circles)

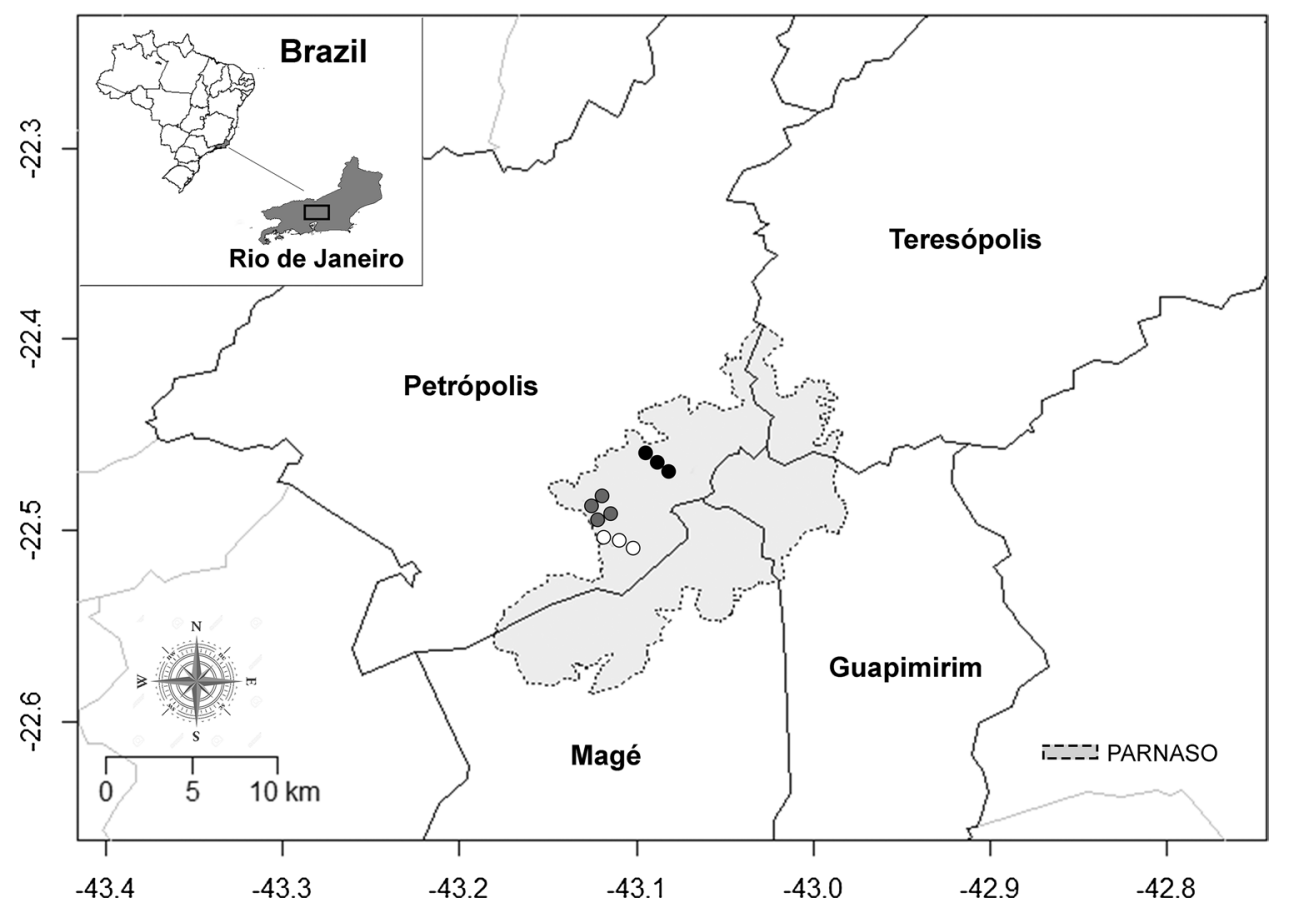


genus Akodon Meyen, 1833 and Oligoryzomys Bangs, 1900 were identified by counting the diploid number.

The animals were captured under authorization from the Chico Mendes Institute for Biodiversity Conservation (ICMBIO, license number 45839-1). All procedures followed the guidelines for capturing, handling and caring for the animals of the Oswaldo Cruz Foundation Ethics Committee on Animal Use (CEUA license number LW-39/14). Biosecurity techniques and personal safety equipment were used during all procedures involving animal handling and biological sampling (Lemos and D'Andrea 2014).

Nematodes, trematodes, cestodes and acanthocephalans were recovered from the lungs, bile ducts, stomach, small intestine, cecum, thoracic and abdominal cavities and washed in saline solution $(0.85 \% \mathrm{NaCl})$. Some specimens were fixed in AFA (93 parts $70 \%$ ethanol, five parts $0.4 \%$ formol and two parts $100 \%$ acetic acid), and others were stored in $70 \%$ ethanol for further molecular analysis. The nematodes were clarified in lactophenol. Trematodes, cestodes and acanthocephalans were stained with Langeron's carmine or Delafield's hematoxylin, differentiated with $0.5 \%$ hydrochloric acid, dehydrated in a growing alcoholic series, diaphanized in methyl salicylate and fixed in Canada balsam for permanent preparation (Amato et al. 1991). The taxonomic identification of these parasites was based on Travassos (1937), Khalil et al. (1994), Vicente et al. (1997), Jones et al. (2005), Bray et al. (2008), Anderson et al. (2009) and Amin (2013).

Voucher specimens of small mammals were deposited in the scientific collection of the Department of Vertebrates of the National Museum of Rio de Janeiro (MN numbers of each species: $84000,84001,84007,84185,84187,84189$, $84191,84197,84203,84205,84206$ and 84227). Voucher specimens of the helminths were deposited in the Helminthological Collection of the Oswaldo Cruz Institute in Rio de Janeiro (CHIOC numbers: 38321, 38322, 38323, 38556, 38557, 38558, 38559, 38560, 38561, 38562 and $38563)$.

\section{Habitat measurements}

Extrinsic environmental variables were measured at each station where hosts were captured in order to characterize the habitat. Variables were taken considering the locations where traps were placed and toward adjacent points (north, south, east and west), about $1.5 \mathrm{~m}$ distant from the central point, encompassing an area of $9 \mathrm{~m}^{2}$ around the traps (adapted from Freitas et al. 2002).

Quantitative variables included canopy height, percentage of canopy cover, percentage of litter cover, percentage of soil exposure, vegetation cover in soil, percentage of rock outcrops, number of trees with more than $1 \mathrm{~m}$ height, number of trees with diameter at breast height $\geq 5$ and density of vertical leaf obstruction (herbaceous and woody parts) at $50 \mathrm{~cm}$ to $1 \mathrm{~m}$ height. Qualitative variables were evaluated by the presence or absence of water courses, midstory at $1-5 \mathrm{~m}$, midstory at 5 to $1 \mathrm{~m}$, midstory above $10 \mathrm{~m}$ and by the presence and abundance (few, regular, or many) of vines and bamboos.

\section{Data analysis}

The overall helminth species richness was considered as the number of species found, and the average species richness was considered as the number of helminth species in each infracommunity divided by the number of hosts analyzed. Parasitological parameters (mean abundance and prevalence) were calculated for each species of helminth according to Bush et al. (1997) for infracommunities and component communities. The mean abundance was considered as the total number of individuals of a particular helminth species divided by the number of small mammals examined. The prevalence of each species was calculated as the proportion of small mammals infected for a given helminth species in relation to the total number of hosts analyzed.

We investigated the relative importance of environmental variables, host attributes and spatial variables on the variation in species abundance for the metacommunities analyzed. This analysis was performed for both component community scale (considering each infected host species as a site) and infracommunity scale (considering each individual host as a site), as well as for the each taxonomic order (rodents and marsupials) and for the entire dataset for both scales (infracommunity and component community). The bionomic and ecological data of the small mammals were considered as host attributes: host gender, host body mass, host diet (frugivorous/granivorous, frugivorous/omnivorous and insectivorous/omnivorous) based on Paglia et al. (2012), host species abundance (only for infracommunity scale) and helminth species richness for each infracommunity and component community analyzed. The host species abundance was estimated as the number of individuals of each species captured per transect.

In order to reduce the number of habitat variables in the analyses, a principal coordinate analysis ( $\mathrm{PCoA}$ ) was performed with these variables. The scores of the first two axes of the PCoA were correlated with the habitat variables measured in order to identify those that were more associated with each of these axes using Spearman's correlation. The extrinsic environmental variables for component community were considered as the means of each habitat variable to small mammal capture stations.

The spatial variables, which represent how species composition varies in space, were determined by the geographic coordinates taken at each capture station, using the principal coordinates analysis of neighbor matrices 
(PCNM), based on a Euclidian distance matrix among the studied sites. This analysis is adequate for community data from multiple sites across space (Legendre et al. $2005)$. The PCNM provides a series of spatial eigenvectors divided in three scales (Borcard and Legendre 2002), where the first vectors represent variation in broad spatial scale (among localities), the intermediate vectors represent medium spatial scale (among transects) and the last vectors represent variation in small spatial scale (among capture stations within the same transect).

The association of environmental variables, host attributes and spatial variables with species abundance matrix of metacommunities was investigated using redundancy analysis (RDA, Rao 1964), considering helminth species abundance as response variable, and environmental variables, host attributes and spatial variables as explanatory variables. Prior to this analysis, species abundance matrices were transformed using Hellinger distance method in order to adequate the data for RDA (Legendre and Gallagher 2001). A stepwise selection (forward stepwise selection using the "ordiR2Step" function) was performed from the global models (Blanchet et al. 2008) to identify which environmental and spatial variables better explained helminth species abundance. This analysis used the stopping criterion based on the global adjusted $R^{2}$. The significance of each model was obtained by ANOVA with 1000 permutations. Statistically significant models were used as components of the Variation Partitioning analysis performed using the "varpart" function. In this analysis, RDA and ANOVA were also used to run the models and test their significance, respectively, in order to calculate the variation attributable to each set of explanatory variable.

We calculated the multiple-site beta diversity for both infracommunity and component community scales and decomposed it into components of balanced variation in abundance (i.e., turnover of individuals) and abundance gradients (i.e., nestedness) to investigate whether diversity is driven by loss or replacement of helminth specimens in the metacommunity studied according to Baselga (2017). This analysis was performed from a dissimilarity matrix calculated by the Bray-Curtis index, considering the helminth species abundance for each infracommunity and the mean helminth species abundance for each component community.

PCNM, Spearman Correlation, ANOVA, RDA, and Variation Partitioning were performed in the vegan package (Oksanen et al. 2018), PCoA in the ape package (Paradis and Schliep 2018) and beta diversity in the betapart package (Baselga et al. 2018), in R software version 3.6.1 (R Core Team 2019). The level of significance adopted was $5 \%$ in all analyses.

\section{Results}

Seventy-three specimens comprising 12 species of small mammals were infected by one or more helminth species, including eight sigmodontine rodents, one echimyid rodent, and three didelphimorph marsupials (Table 1). A total of 29 helminth morphospecies were recovered: 27 from the gastrointestinal tract, one from the lungs and one from the abdominal cavity, representing 22 nematodes, four cestodes, two trematodes and one acanthocephalan (Table 1). A few taxa were not identified at specific level due to the absence of diagnostic taxonomic characters.

Considering the whole community of small mammals, $D$. aurita had the highest total $(n=12)$ and average $(\bar{x}=4.25)$ species richness of helminths. Didelphis aurita was infected by three helminth phyla (Table 1) and had the highest values of prevalence and/or abundance of Aspidodera raillieti Travassos, 1913, Cruzia tentaculata (Rudolphi 1819) Travassos (1922), Heterostrongylus heterostrongylus Travassos, 1925, Turgida turgida (Rudolphi 1819) Travassos, 1919 and Viannaia hamata Travassos, 1914. Among rodents, the highest prevalence and abundance of helminths were observed for Stilestrongylus aculeata Travasssos, 1918, recovered from Akodon montensis Thomas 1913, and Stilestrongylus lanfrediae Souza, Digiani, Simões, Luque, Rodrigues-Silva \& Maldonado Jr., 2009, recovered from Oligoryzomys flavescens (Waterhouse 1837) and Oligoryzomys nigripes (Olfers 1818) (Table 1).

The first two axes of the principal coordinate analysis (PCoA1 and PCoA2) of the habitat variables explained 68\% of the data variation, and these were used as the extrinsic environmental variables. Except for the variables "percentage of rock outcrops" and "density of vertical leaf obstruction," all variables were significantly related to either the first or the second PCoA axis, or both. Variables most correlated with PCoA1 were associated with horizontal heterogeneity of vegetation, and those most correlated with PCoA2 were related to vertical vegetation structure. For spatial variables, PCNM analysis resulted in 28 positive eigenvectors, which were used in the RDA. Broad-scale variables included PCNM1 to PCNM9, medium scale PCNM10 to PCNM19 and small scale PCNM20 to PCNM28.

Host attributes and spatial variables influenced the abundance of helminth species in metacommunities for rodents and marsupials together, and for rodents alone at infracommunity level (Table 2). In both cases, however, extrinsic environmental variables (PCoA1 and PCoA2) had no relationship with helminth species abundance (Table 2). Statistically significant relationships were observed for host body mass, host diet and spatial variables (Tables 2 and 3). The significant spatial variables were mostly represented by vectors that explained differences along the broad spatial 
Table 1 Number of analyzed and infected small mammals with helminths, average richness (with range of helminth species richness for infracommunities), prevalence (with 95\% confidence interval), and mean abundance \pm standard deviation in the Serra dos Órgãos National Park, Petrópolis, Rio de Janeiro, Brazil

\begin{tabular}{|c|c|c|c|c|}
\hline Host species and helminth species & $\begin{array}{l}\text { Analyzed hosts } \\
\text { (infected hosts) }\end{array}$ & $\begin{array}{l}\text { Average richness (richness } \\
\text { range of infracommunities) }\end{array}$ & Prevalence $(95 \% \mathrm{CI})$ & $\begin{array}{l}\text { Mean abun- } \\
\text { dance } \pm \text { Standard } \\
\text { deviation }\end{array}$ \\
\hline Abrawayaomys ruschii & $2(1)$ & $0.5(0-1)$ & & \\
\hline Stilestrongylus aculeata & & & $50(40.59-59.40)$ & $1.5 \pm 2.12$ \\
\hline Akodon montensis & $62(19)$ & $0.45(0-3)$ & & \\
\hline Canaania obesa & & & $4.8(1-1.35)$ & $0.25 \pm 1.41$ \\
\hline Protospirura numidica criceticola & & & $4.8(1-13.5)$ & $0.06 \pm 0.30$ \\
\hline Rodentolepis akodontis & & & $6.5(1.8-15.7)$ & $0.11 \pm 0.48$ \\
\hline Stilestrongylus aculeata & & & $17.7(9.2-29.5)$ & $8.27 \pm 33.97$ \\
\hline Stilestrongylus eta & & & $6.5(1.8-15.7)$ & $2.19 \pm 14.47$ \\
\hline Trichofreitasia lenti & & & $4.8(1-13.5)$ & $0.04 \pm 0.21$ \\
\hline Blarinomys breviceps & $4(1)$ & $0.25(0-1)$ & & \\
\hline Cestoda 1 & & & $25(23.4-26.5)$ & $0.25 \pm 0.5$ \\
\hline Delomys dorsalis & $8(2)$ & $0.25(0-1)$ & & \\
\hline Alippistrongylus sp. & & & $12.5(10.1-14.8)$ & $0.37 \pm 1.06$ \\
\hline Rodentolepis akodontis & & & $12.5(11.7-13.2)$ & $0.12 \pm 0.35$ \\
\hline Oligoryzomys flavescens & $2(2)$ & $1.5(1-2)$ & & \\
\hline Guerrerostrongylus zetta & & & $50(46.8-53.1)$ & $0.50 \pm 0.57$ \\
\hline Stilestrongylus lanfrediae & & & $100(71-128.2)$ & $13.5 \pm 6.36$ \\
\hline Oligoryzomys nigripes & $43(23)$ & $0.69(0-2)$ & & \\
\hline Guerrerostrongylus zetta & & & $20.9(17.3-24.5)$ & $1.16 \pm 3.77$ \\
\hline Stilestrongylus lanfrediae & & & $48.8(15.1-82.5)$ & $19.41 \pm 35.21$ \\
\hline Oxymycterus quaestor & $4(1)$ & $0.25(0-1)$ & & \\
\hline Litomosoides sp. & & & $25(0-87.7)$ & $10 \pm 20$ \\
\hline Thaptomys nigrita & $4(2)$ & $1(0-3)$ & & \\
\hline Protospirura numidica criceticola & & & $50(39.6-60.3)$ & $2.25 \pm 3.30$ \\
\hline Pterygodermatites sp. & & & $25(21.8-28.1)$ & $0.5 \pm 1$ \\
\hline Stilestrongylus sp. & & & $25(23.4-26.5)$ & $0.25 \pm 0.5$ \\
\hline Trinomys dimidiatus & $17(5)$ & $0.35(0-2)$ & & \\
\hline Heligmostrongylus sp. & & & $23.5(17.2-29.8)$ & $1.41 \pm 4.15$ \\
\hline Trichuris sp. & & & $17(16.1-19.1)$ & $0.29 \pm 0.98$ \\
\hline Didelphis aurita & $12(12)$ & $4.25(2-8)$ & & \\
\hline Aspidodera raillieti & & & $75(27.16-122.83)$ & $18.58 \pm 26.42$ \\
\hline Cruzia tentaculata & & & $91.66(71.85-111.48)$ & $19 \pm 10.94$ \\
\hline Globocephalus marsupialis & & & $8.33(5.19-11.46)$ & $0.5 \pm 1.73$ \\
\hline Heterostrongylus heterostrongylus & & & $58.33(40.10-76.56)$ & $5 \pm 10.07$ \\
\hline Travassostrongylus orloffi & & & $8.33(5.19-11.46)$ & $0.5 \pm 1.73$ \\
\hline Trichuris didelphis & & & $8.33(6.24-10.42)$ & $0.33 \pm 1.15$ \\
\hline Trichuris minuta & & & $8.33(7.81-8.85)$ & $0.08 \pm 0.28$ \\
\hline Turgida turgida & & & $58.33(43.06-73.59)$ & $7.75 \pm 8.43$ \\
\hline Viannaia hamata & & & $66.66(0-303.82)$ & $88 \pm 131.01$ \\
\hline Rhopalias coronatus & & & $25(15.95-65.95)$ & $7.58 \pm 22.62$ \\
\hline Matevothaenia sp. & & & $8.33(6.24-10.42)$ & $0.33 \pm 1.15$ \\
\hline Oligacanthorhynchus microcephalus & & & $8.33(6.24-10.42)$ & $0.16 \pm 0.57$ \\
\hline Marmosops incanus & $3(1)$ & $0.33(0-1)$ & & \\
\hline Cestoda 2 & & & $33.33(22.88-43.78)$ & $1.66 \pm 2.88$ \\
\hline Philander quica & $6(4)$ & $1.66(0-3)$ & & \\
\hline Aspidodera raillieti & & & $66.66(46.80-86.52)$ & $6.16 \pm 7.75$ \\
\hline
\end{tabular}


Table 1 (continued)

\begin{tabular}{|c|c|c|c|c|}
\hline Host species and helminth species & $\begin{array}{l}\text { Analyzed hosts } \\
\text { (infected hosts) }\end{array}$ & $\begin{array}{l}\text { Average richness (richness } \\
\text { range of infracommunities) }\end{array}$ & Prevalence $(95 \% \mathrm{CI})$ & $\begin{array}{l}\text { Mean abun- } \\
\text { dance } \pm \text { Standard } \\
\text { deviation }\end{array}$ \\
\hline Cruzia tentaculata & & & $33.33(0-155.12)$ & $21.16 \pm 47.57$ \\
\hline Turgida turgida & & & $33.33(30.23-36.43)$ & $0.66 \pm 1.21$ \\
\hline Viannaia sp. & & & $33.33(30.23-36.43)$ & $0.66 \pm 1.21$ \\
\hline
\end{tabular}

Table 2 A priori association of environmental variables, host attributes and spatial variables with the species abundance matrix of helminth metacommunities in the Serra dos Órgãos National Park, Petrópolis, Rio de Janeiro, Brazil

\begin{tabular}{|c|c|c|c|c|c|c|c|c|c|c|}
\hline \multirow[t]{3}{*}{ Host taxa } & \multirow[t]{3}{*}{ Scales } & \multicolumn{9}{|c|}{ Variables } \\
\hline & & \multicolumn{3}{|c|}{ Spatial } & \multicolumn{3}{|c|}{ Host attributes } & \multicolumn{3}{|c|}{$\begin{array}{l}\text { Environmental } \\
\text { (extrinsic) }\end{array}$} \\
\hline & & $\mathrm{DF}$ & $\mathrm{F}$ & $\mathrm{P}$ & DF & $\mathrm{F}$ & $\mathrm{P}$ & $\mathrm{DF}$ & $\mathrm{F}$ & $\mathrm{P}$ \\
\hline \multirow[t]{2}{*}{ Marsupials and rodents } & Component community & - & - & - & 4 & 1.03 & 0.370 & 2 & 0.95 & 0.608 \\
\hline & Infracommunity & 7 & 2.98 & 0.001 & 3 & 12.04 & 0.001 & 2 & 1.36 & 0.151 \\
\hline \multirow[t]{2}{*}{ Rodents } & Component community & - & - & - & 3 & 1.04 & 0.416 & 2 & 0.80 & 0.812 \\
\hline & Infracommunity & 5 & 3.89 & 0.001 & 2 & 14.79 & 0.001 & 2 & 1.13 & 0.294 \\
\hline Marsupials & Infracommunity & 5 & 0.63 & 0.947 & 1 & 2.94 & 0.018 & 2 & 1.14 & 0.331 \\
\hline
\end{tabular}

$\mathrm{DF}$, degrees of freedom; F, Variation between sample means/variation within the samples; $P, p$ value

Table 3 Variance Partitioning analyses based on redundancy analysis in order to determine the variation in helminth species abundance in the Serra dos Órgãos National Park, Petrópolis, Rio de Janeiro, Brazil

\begin{tabular}{|c|c|c|c|c|c|c|}
\hline Metacommunities & Partition & Analyzed variables & DF & $\begin{array}{l}\text { Variation } \\
\text { explained } \\
(\%)\end{array}$ & $\mathrm{F}$ & $\mathrm{P}$ \\
\hline \multirow{6}{*}{$\begin{array}{l}\text { Marsupial and rodent } \\
\text { infracommunities }\end{array}$} & Host attributes & Body mass and diet host & 3 & 24.8 & 8.90 & 0.001 \\
\hline & Spatial & $\begin{array}{l}\text { PCNM1, PCNM3, PCNM5, PCNM8, PCNM9, } \\
\text { PCNM12 and PCNM23 }\end{array}$ & 7 & 0.9 & 1.09 & 0.344 \\
\hline & Host attributes + spatial & & 10 & 25.4 & 3.45 & 0.002 \\
\hline & Host attributes only & & 3 & 24.6 & 8.13 & 0.001 \\
\hline & Spatial only & & 7 & 0.6 & 1.08 & 0.352 \\
\hline & Residual (unexplained) variation & & - & 74.6 & - & - \\
\hline \multirow[t]{6}{*}{ Rodent infracommunities } & Host attributes & Body mass and diet host & 2 & 11.8 & 4.67 & 0.01 \\
\hline & Spatial & $\begin{array}{l}\text { PCNM3, PCNM7, PCNM8, PCNM12 and } \\
\text { PCNM20 }\end{array}$ & 5 & 6.4 & 1.75 & 0.117 \\
\hline & Host attributes + spatial & & 7 & 12.7 & 2.13 & 0.03 \\
\hline & Host attributes only & & 2 & 6.2 & 2.77 & 0.043 \\
\hline & Spatial only & & 5 & 0.9 & 1.10 & 0.369 \\
\hline & Residual (unexplained) variation & & - & 87.3 & - & - \\
\hline
\end{tabular}

The results indicate the variation explained by each gradient, host attributes and spatial variables (eigenvectors of the PCNM), the variation explained by both gradients together (host attributes + spatial variables), and the variation in each gradient without the overlapped variation (host attributes only or spatial variables only)

$\mathrm{DF}$, degrees of freedom; F, Variation between sample means/variation within the samples; $P, p$ value

scale (PCNM1, PCNM3, PCNM5, PCNM7, PCNM8 and PCNM9; Table 3). At medium and small spatial scales, only three variables were significant (PCNM12, PCNM20 and PCNM23; Table 3). At the infracommunity level for marsupials, only helminth species richness (host attribute) influenced helminth abundance of these hosts $(F=2.94$,
$\mathrm{DF}=1, P=0.01$ ). At the component community level, there was no statistically significant influence of the components investigated in the helminth species abundance, considering rodents and marsupials together $(\mathrm{F}=1.03, \mathrm{DF}=4, P=0.37$ for host attributes; $\mathrm{F}=0.95, \mathrm{DF}=2, P=0.60$ for environmental variables $)$ and rodents alone $(\mathrm{F}=1.04, \mathrm{DF}=3$, 
$P=0.41$ for host attributes; $\mathrm{F}=0.80, \mathrm{DF}=2, P=0.81$ for environmental variables).

Host body mass, host diet and spatial variables (PCNM vectors cited above) together accounted for approximately $25.4 \%$ of the variation in helminth species abundance at the infracommunity level considering rodents and marsupials, and approximately $12.7 \%$ considering only rodents (Table 3). Among these variables, host attributes represented most of the variation in the abundance of the metacommunities investigated (Table 3). When analyzed without the influence of spatial variables, the variation accounted $24.6 \%$ for rodents and marsupials together, and $6.2 \%$ for rodents (Table 3).

The overall beta diversity among infracommunities was 0.98 , and it among component communities was 0.96. Considering each component of beta diversity, metacommunity showed larger turnover than nestedness for their helminth species at both infracommunity and component community levels (infracommunity: turnover $=0.93$ and nestedness $=0.05$; component community: turnover $=0.86$ and nestedness $=0.10$ ), indicating more species replacement than species loss along the environmental gradient (Fig. 2).

\section{Discussion}

Our analyses indicate that hosts attributes were the most important factors influencing abundance of helminth species of metacommunities at the infracommunity scale, for marsupials and rodents together, and for each of these orders separately. These findings corroborate, in part, our first hypothesis. On the other hand, extrinsic habitat variables were not recovered as important predictors for the studied helminth metacommunities, although external environment factors may influence the occurrence of parasites (Cardoso et al. 2016).

Concerning the host attributes analyzed, differences among hosts regarding their body mass and diet explained more than $20 \%$ of the variation in helminth species abundance. In fact, host body mass (or size) and host feeding habit have been pointed out as some of the main determinants of variation in parasite species richness or occurrence (Dallas and Presley 2014, Kamiya et al. 2014). In a metaanalysis study on determinants of parasite species richness, a positive relationship between host body size and parasite species richness was observed for mammals and helminths, and the authors proposed that the species-area relationship may also be applied to parasites, as larger host species provide greater space to parasites (Kamiya et al. 2014). In addition, hosts with large body size may harbor more
Fig. 2 Relationship between balanced variation in abundance (turnover) and abundance gradients (nestedness) in two levels in the Serra dos Órgãos National Park, Petrópolis, state of Rio de Janeiro, Brazil: left: infracommunities, considering the abundance of helminth species in each individual host; right: component communities, considering the abundance of helminth species in each host species
Infracommunities

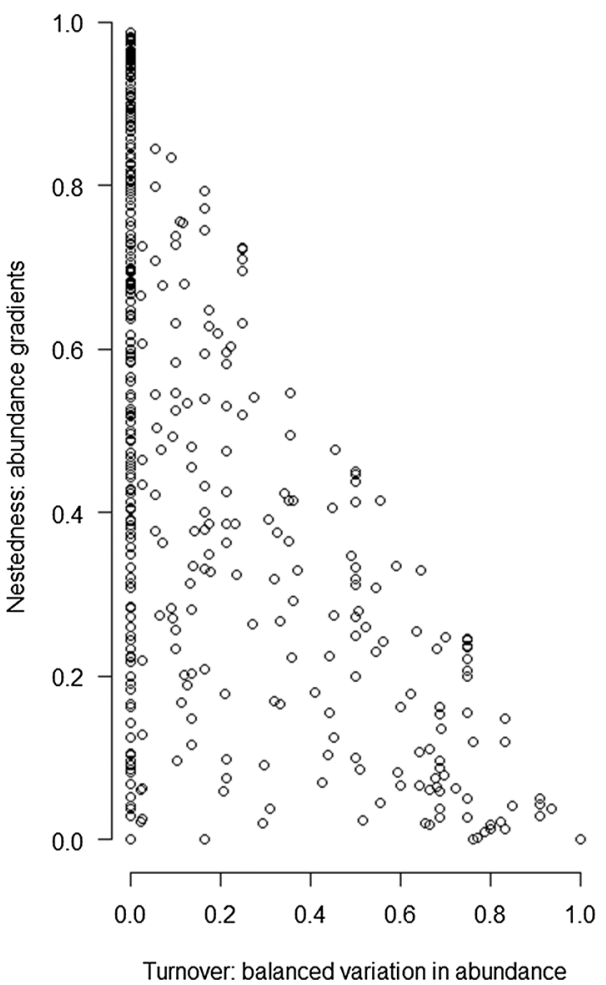

Component communities

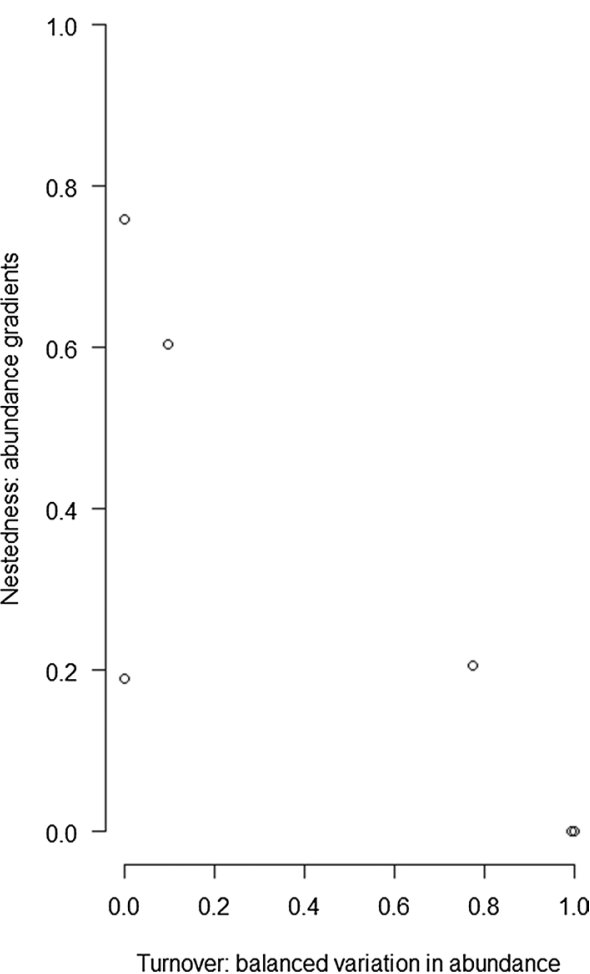


parasites probably because they have larger intake of food items as well as the amount of food than smaller ones, which increases their chance to acquire parasites, thus making the encounter filter with parasites wider. Moreover, hosts with larger diet amplitude, i.e., consuming a wider range of food items, may have larger parasite diversity in relation to hosts with more restricted diets. Thus, the common opossum, $D$. aurita, is expected to have a larger helminth species richness than small sigmodontine rodents not only because it is the host with the largest body size among analyzed taxa, but also because it is an omnivorous species that feeds on several items, including invertebrates (Paglia et al. 2012), which may act as intermediate hosts of some helminth species. In the present study, the nematodes $H$. heterostrongylus and $T$. turgida, the cestode Mathevotaenia sp., the trematode Rhopalias coronatus (Rudolphi 1819) Stiles and Hassall 1898 and the acanthocephala Oligacanthorhynchus microcephalus (Rudolphi 1819) Schmidt 1972, which infected D. aurita, have indirect life cycles, using invertebrates as intermediate hosts (Anderson 2000). Thus, the feeding of invertebrates by the common opossum may favor the acquisition of these parasites. In addition, D. aurita exhibits large movements (Gentile and Cerqueira 1995), which may increase its probability to encounter parasites in the environment.

Although helminth species richness was another hostrelated variable that influenced the variation in the parasite species abundance, it was only significant for marsupials' infracommunities. Marsupials had more discordant values of helminth species richness than rodents. Didelphis aurita and Philander quica (Temminck 1824) showed high average species richnesses, but Marmosops incanus (Lund 1841) displayed low species richness, corroborating this variation among marsupials.

Spatial distribution variables represented another important predictor for variation in species abundance of helminth metacommunities at infracommunity scale, but only when the host attributes were also considered in the analysis. This result suggests that the influence of the spatial variation in these parasites is less important than the variation in host characteristics. The differences in metacommunities were better observed among localities (Bonfim, Uricanal and Barragem do Caxambu) than within each one, as most of the significant variables represented the broad spatial scale. The selection of these variables suggests that movements of host individuals allowed a certain homogenization in the parasite species abundance and composition, predominantly in the small spatial scale (within transects) and within each host species. In this case, there was a larger sharing of parasite species among geographically close infracommunities than among infracommunities from different localities, considering the short sampling period. In fact, our previous studies have indicated different helminth distribution patterns according to the spatial scale investigated, so that environmental gradients with increasing spatial scale may promote differences in the composition of helminth metacommunities (Cardoso et al. 2018; Costa-Neto et al. 2019). In addition, differences in the small mammal fauna among localities of the present study may also have contributed to this dissimilarity in helminth species abundance and composition in the environment because of the high host specificity of the helminths. Other studies have also shown that larger spatial scales could represent barriers to the distribution of viruses among rodents in the American continent (Nieto-Rabiela et al. 2018) and for free-living nematodes in European lakes (Dümmer et al. 2016). Another studies demonstrated that latitudinal gradients can affect the probability of parasite occurrence and diversity (Guernier et al. 2004; Mihaljevic et al. 2018).

The residual variation in the partitioning analyses at the infracommunity scales and the absence of significant variables in the RDA analysis at component community scale suggest that parasite characteristics may also influence their distribution. The genetic variability among individuals may result in differences among populations in the parasitological parameters, such as prevalence and abundance, influencing their distribution and occurrence (Poulin 2007). Other host attributes could also influence the parasite metacommunity structure, such as taxonomic distance, locomotor habit, home range size, niche breadth and longevity (Dallas and Presley 2014). The residual variation observed may also be due to the small sample size of the rare host species, such as Abrawayaomys ruschii and Blarinomys breviceps (Cerboncini et al. 2014; Machado et al. 2016). The small number of infracommunities analyzed for these hosts may have influenced their parasite diversity. Indeed, rare species may not be detected in biodiversity surveys, influencing the estimates of species diversity (Chao et al. 2014). Thus, the effects of the sample size in the residual variation should also be considered.

Our results indicated that the helminth beta diversity was similar for infracommunities and component communities, which may be associated with different susceptibilities of infection, opportunities for exposure and development of the parasites among hosts on these two scales (Poulin 2007). We observed more replacements than loss of individuals of some helminth species along the metacommunities, which can be attributed to the processes of host-parasite coevolution, resulting in a high host specificity and low helminth sharing among hosts for most of the species (Dallas and Presley 2014). Previous studies on rodent parasitic metacommunities also indicated that the diversity of parasite species was determined by a greater species replacements than species loss, probably as a result of host specificity (Dallas and Presley 2014), or host phylogenetic distance and host functional characteristics, as body mass, litter size, number of litters per year and trophic guild (Nieto-Rabiela et al. 2018). 
Indeed, there were few instances of helminth species sharing among different rodent species, and none between rodents and marsupials. This result supports the second hypothesis that species turnover was more important than species loss in the community structure at both infracommunities and component community scales.

According to Márquez et al. (2016), local processes in community structure may be mostly influenced by stochastic events driven by ecological interactions among species, whereas regional processes are related to community characteristics and to results produced by local interactions. The combined influence of geographic variables (spatial scales) with host attributes indicated the existence of spatial autocorrelation in host distribution, which may have led to a heterogeneity in helminth composition and abundance throughout the metacommunity. Different environmental filters, such as host distribution and other host characteristics, may enable the establishment of parasites (Guégan et al. 2005) and shape the transmission dynamics of these organisms in the metacommunity (Dallas and Presley 2014). Concluding, the association of spatial variables with helminth abundance in the studied metacommunities indicated that the variation in the helminth distribution along the environmental gradient composed of rodents and marsupials was more influenced by broad spatial scale factors than by smaller ones as a result of evolutionary processes involved in the community structure. A larger turnover in relation to species loss observed in the metacommunities resulted in a high host specificity of the helminths and in structured metacommunities due to the processes of host-parasite coevolution, thus influencing the diversity of these parasites.

Acknowledgements The authors would like to thank the staff and students of Laboratório de Biologia e Parasitologia de Mamíferos Silvestres Reservatórios at Fiocruz, Setor de Mastozoologia, Museu Nacional/UFRJ and Laboratório de Vertebrados at UFRJ for helping in the field work; to Dr. R. Cerqueira for the ICMBio license; Dr. J. Souza for helping in the helminths identification; and Dr. R. Cerqueira and Dr. P. C. Estrela for the coordination of the general project PPBio Rede BioM.A. We would also like to thank Dr. M. V. Vieira of Laboratório de Vertebrados at UFRJ for his valuable comments on a previous version of the manuscript. This project was financially supported by Conselho Nacional de Desenvolvimento Científico e TecnológicoCNPq-PPBio Rede BioM.A (457524/2012-0), Instituto Oswaldo Cruz (IOC-FIOCRUZ), Laboratório de Vertebrados (UFRJ) and Programa de Pós-Graduação em Ciências Veterinárias (UFRRJ) and Programa de Pós-Graduação em Biodiversidade e Saúde (IOC-FIOCRUZ). TSC, $\mathrm{CB}$ and SFCN received grants from Coordenação de Aperfeiçoamento de Pessoal de Nível Superior (CAPES)-Brasil-Finance code 001. ROS received grants from Fundação Carlos Chagas Filho de Amparo à Pesquisa do Estado do Rio de Janeiro (FAPERJ). MW, JLL and RG received grants from Conselho Nacional de Desenvolvimento Científico e Tecnológico-CNPq.

\section{Compliance with ethical standard}

Conflict of interest The authors declare that they have no conflict of interest.
Open Access This article is licensed under a Creative Commons Attribution 4.0 International License, which permits use, sharing, adaptation, distribution and reproduction in any medium or format, as long as you give appropriate credit to the original author(s) and the source, provide a link to the Creative Commons licence, and indicate if changes were made. The images or other third party material in this article are included in the article's Creative Commons licence, unless indicated otherwise in a credit line to the material. If material is not included in the article's Creative Commons licence and your intended use is not permitted by statutory regulation or exceeds the permitted use, you will need to obtain permission directly from the copyright holder. To view a copy of this licence, visit http://creativecommons.org/licenses/by/4.0/.

\section{References}

Amato, J. F. R., Boeger, W. A., \& Amato, S. B. (1991). Protocolos para Laboratório-Coleta e Processamento de Parasitos de Pescado. UFRRJ, Seropédica: Impr. Univ.

Amin, O. M. (2013). Classification of the Acanthocephala. Folia Parasitologica, 60, 273-305.

Anderson, R. C. (2000). Nematode parasites of vertebrates their development and transmission. Farnham Royal: CABI.

Anderson, R. C., Chabaud, A. G., \& Willmott, S. (2009). Keys to the nematode parasites of vertebrates. Wallingford: CABI.

Ayoade, J.O. 1986. Introdução a Climatologia para os Trópicos. Ed. Difel, São Paulo

Baselga, A. (2010). Partitioning the turnover and nestedness components of beta diversity. Global Ecology and Biogeography, 19, 134-143.

Baselga, A. (2017). Partitioning abundance-based multiple-site dissimilarity into components: Balanced variation in abundance and abundance gradients. Methods in Ecology and Evolution, 8, 799-808.

Baselga, A., Orme, D., Villeger, S., De Bortoli, J., \& Leprieur, F.. 2018. Betapart: Partitioning beta diversity into turnover and nestedness components. R package version 1.5.0. URL https://CRAN.R-proje ct.org/package $=$ betapart

Blanchet, F. G., Legendre, P., \& Borcard, D. (2008). Forward selection of explanatory variables. Ecology, 89, 2623-2632.

Borcard, D., \& Legendre, P. (2002). All-scale spatial analysis of ecological data by means of principal coordinates of neighbour matrices. Ecological Modelling, 153, 51-68.

Boullosa, R. G., dos Santos Cardoso, T., da Costa-Neto, S. F., Teixeira, B. R., de Freitas, T. P. T., Júnior, A. M., \& Gentile, R. 2019. Helminth community structure of three sigmodontine rodents in the Atlantic forest, southern Brazil. Oecologia Australis [First view]: $1-22$.

Braga, C., Oliveira, J. A., \& Cerqueira, R. (2017). Metacomunidades: uma introdução aos termos e conceitos. Oecologia Australis, 21, $108-118$.

Bray, R. A., Gibson, D. I., \& Jones, A. (2008). Keys to the trematoda (Vol. 3). Wallingford: CABI.

Bush, A. O., Lafferty, K. D., Lotz, J. M., \& Shostak, A. W. (1997). Parasitology meets ecology on its own terms: Margolis et al. revisited. Journal of Parasitology, 83, 575-583.

Cardoso, T. S., Braga, C. A. C., Macabu, C. E., Simões, R. O., CostaNeto, S. F., Maldonado-Júnior, A., et al. (2018). Helminth metacommunity structure of wild rodents in a preserved area of the Atlantic Forest, Southeast Brazil. Revista Brasileira de Parasitologia Veterinária, 27, 495-504.

Cardoso, T. S., Simões, R. O., Luque, J. L., Maldonado, A., \& Gentile, R. (2016). The influence of habitat fragmentation on helminth communities in rodent populations from a Brazilian Mountain Atlantic Forest. Journal of Helminthology, 90, 460-468. 
Castro, R. G. B. M., Costa-Neto, S. F., Maldonado Júnior, A., \& Gentile, R. (2017). Ecological aspects of nematode parasites of Didelphis aurita (Didelphimorphia, Didelphidae) in urban-sylvatic habitats in Rio de Janeiro, Brazil. Oecologia Australis, 21, 54-61.

Cerboncini, R. A. S., Zanata, T. B., Cunha, W. L., Rorato, A. M., Calefi, A. S., Sbegen, M. R., et al. (2014). Distribution extension of Abrawayaomys ruschii Cunha and Cruz, 1979 (Rodentia: Cricetidae) with the first records in the state of Paraná, southern Brazil. Check List, 10, 660-662.

Chao, A., Gotelli, N. J., Hsieh, T. C., Sander, E. L., Ma, K. H., Colwell, R. K., et al. (2014). Rarefaction and extrapolation with Hill numbers: a framework for sampling and estimation in species diversity studies. Ecological Monographs, 84, 45-67.

Combes, C. (2001). Parasitism: The ecology and evolution of intimate interactions. Chicago: University of Chicago Press.

Costa, N., Cardoso, T. S., Costa-Neto, S. F., Maldonado Júnior, A., $\&$ Gentile, R. (2019). Metacommunity structure of helminths of Necromys lasiurus (rodentia: sigmodontinae) in different land use areas in the Brazilian Cerrado. Journal of Parasitology, 105, 271-282.

Costa-Neto, S. F., Cardoso, T. S., Boullosa, R. G., Maldonado, A., \& Gentile, R. (2019). Metacommunity structure of the helminths of the black-eared opossum Didelphis aurita in peri-urban, sylvatic and rural environments in south-eastern Brazil. Journal of Helminthology, 93, 720-731.

Dallas, T., \& Presley, S. J. (2014). Relative importance of host environment, transmission potential and host phylogeny to the structure of parasite metacommunities. Oikos, 123, 866-874.

Dümmer, B., Ristau, K., \& Traunspurger, W. (2016). Varying patterns on varying scales: A metacommunity analysis of nematodes in European lakes. PLOS ONE, 11, e0151866.

Fernandes, I. M., Henriques-Silva, R., Penha, J., Zuanon, J., \& PeresNeto, P. R. (2014). Spatiotemporal dynamics in a seasonal metacommunity structure is predictable: The case of floodplain-fish communities. Ecography, 37, 464-475.

Freitas, S. R., Cerqueira, R., \& Vieira, M. V. (2002). A device and standard variables to describe microhabitat structure of small mammals based on plant cover. Brazilian Journal of Biology, 62, 795-800.

Gentile, R., \& Cerqueira, R. (1995). Movement patterns of five species of small mammals in a Brazilian restinga. Journal of Tropical Ecology, 11, 671-677.

Guégan, J.F., S. Morand \& R. Poulin. 2005. Are there general laws in parasite community ecology? The emergence of spatial parasitology and epidemiology. In F. Thomas, F. Renaud and J.F. Guégan (eds.), Parasitism and Ecosystems. pp. 22-42.

Guernier, V., Hochberg, M. E., \& Guégan, J.-F. (2004). Ecology drives the worldwide distribution of human diseases. PLoS Biology, 2, e141.

Han, B. A., Kramer, A. M., \& Drake, J. M. (2016). Global patterns of zoonotic disease in mammals. Trends in Parasitology, 32, $565-577$.

Heino, J., Soininen, J., Alahuhta, J., Lappalainen, J., \& Virtanen, R. (2017). Metacommunity ecology meets biogeography: Effects of geographical region, spatial dynamics and environmental filtering on community structure in aquatic organisms. Oecologia, 183, 121-137.

Instituto Chico Mendes de Conservação da Biodiversidade (ICMBio). 2018. Parque Nacional da Serra Dos Órgãos (PARNASO). http:// www.icmbio.gov.br/parnaserradosorgaos

Jones, A., Bray, R. A., \& Gibson, D. I. I. (2005). Keys to the trematoda. Wallingford: CABI.

Kamiya, T., O’Dwyer, K., Nakagawa, S., \& Poulin, R. (2014). What determines species richness of parasitic organisms? A meta-analysis across animal, plant and fungal hosts. Biological Reviews, $89,123-134$
Khalil, L. F., Jones, A., \& Bray, R. A. (1994). Keys to the cestode parasites of vertebrates. Wallingford: CABI.

Legendre, P., Borcard, D., \& Peres-Neto, P. R. (2005). Analyzing beta diversity: Partitioning the spatial variation of community composition data. Ecological Monographs, 75, 435-450.

Legendre, P., \& Gallagher, E. D. (2001). Ecologically meaningful transformations for ordination of species data. Oecologia, 129, 271-280.

Leibold, M. A., Holyoak, M., Mouquet, N., Amarasekare, P., Chase, J. M., Hoopes, M. F., et al. (2004). The metacommunity concept: A framework for multi-scale community ecology. Ecology Letters, 7, 601-613.

Leibold, M. A., \& Mikkelson, G. M. (2002). Coherence, species turnover, and boundary clumping: elements of meta-community structure. Oikos, 97, 237-250.

Lemos, E. R. S., \& D'Andrea, P. S. (2014). Trabalho de Campo com Animais: Procedimentos, Riscos e Biossegurança (1ed ed.). Rio de Janeiro: FIOCRUZ.

Machado, F. S., Lima, I. J., Lopes, A. P. M., Moura, A. S., \& Abreu, T. C. K. (2016). New occurrences and biological aspects to four species of rodents (Mammalia: Cricetidae) from Brazil. Revista Agrogeoambiental, 8, 35-51.

Márquez, J., Kolasa, J., \& Sciullo, L. (2016). Local versus regional processes and the control of community structure. Community Ecology, 17, 1-7.

Mihaljevic, J. R., Hoye, B. J., \& Johnson, P. T. J. (2018). Parasite metacommunities: Evaluating the roles of host community composition and environmental gradients in structuring symbiont communities within amphibians. Journal of Animal Ecology, 87, 354-368.

Nieto-Rabiela, F., Suzán, G., Wiratsudakul, A., \& Rico-Chávez, O. (2018). Viral metacommunities associated to bats and rodents at different spatial scales. Community Ecology, 19, 168-175.

Oksanen, J., F. Guillaume Blanchet, M. Friendly, R. Kindt, P. Legendre, D. McGlinn, P.R. Minchin, R.B. O'Hara, G.L. Simpson, P. Solymos, M.H.H. Stevens, E. Szoecs \& H. Wagner. 2018. Vegan: Community ecology Package. URL https://github.com/vegandevs/ vegan

Paglia, A.P., G.A.B. da Fonseca, A.B. Rylands, G. Herrmann, L.M.S. Aguiar, A.G. Chiarello, Y.L.R. Leite, L.P. Costa, S. Siciliano, M.C.M. Kierulff, S.L. Mendes, R.A. Mittermeier \& J. L. Patton. 2012. Annotated Checklist of Brazilian Mammals, $2^{\text {a }}$ Edição, Occas. pap. No. 6. Conserv. Int., Vancouver.

Pakdeenarong, N., Siribat, P., Chaisiri, K., Douangboupha, B., Ribas, A., Chaval, Y., et al. (2014). Helminth communities in murid rodents from southern and northern localities in Lao PDR: the role of habitat and season. Journal of Helminthology, 88, 302-309.

Paradis, E., \& Schliep, K. (2018). ape 5.0: An environment for modern phylogenetics and evolutionary analyses in R. Bioinformatics, 35, 526-528.

Peres-Neto, P. R., \& Legendre, P. (2010). Estimating and controlling for spatial structure in the study of ecological communities. Global Ecology and Biogeography, 19, 174-184.

Philippi, T. E., Dixon, P. M., \& Taylor, B. E. (1998). Detecting trends in species composition. Ecological Applications, 8, 300-308.

Poulin, R. (2007). Evolutionary ecology of parasites (2nd ed.). Princeton: Princeton University Press.

Presley, S. J., Higgins, C. L., \& Willig, M. R. (2010). A comprehensive framework for the evaluation of metacommunity structure. Oikos, 119, 908-917.

Püttker, T., Meyer-Lucht, Y., \& Sommer, S. (2008). Effects of fragmentation on parasite burden (nematodes) of generalist and specialist small mammal species in secondary forest fragments of the coastal Atlantic Forest, Brazil. Ecological Research, 23, 207-215.

R Core Team. 2019. R: A language and environment for statistical computing. R Foundation for Statistical Computing, Vienna, Austria. URL https://www.R-project.org/ 
Rao, C. R. (1964). The use and interpretation of principal component analysis in applied research. Sankhyā: The Indian Journal of Statistics, Series A, 26, 329-358.

Richgels, K. L. D., Hoverman, J. T., \& Johnson, P. T. J. (2013). Evaluating the role of regional and local processes in structuring a larval trematode metacommunity of Helisoma trivolvis. Ecography, 36, 854-863.

Simões, R. O., Gentile, R., Rademaker, V., D’Andrea, P. S., Herrera, H., Freitas, T., et al. (2010). Variation in the helminth community structure of Thrichomys pachyurus (Rodentia: Echimyidae) in two sub-regions of the Brazilian Pantanal: The effects of land use and seasonality. Journal of Helminthology, 84, 266-275.

Soininen, J., McDonald, R., \& Hillebrand, H. (2007). The distance decay of similarity in ecological communities. Ecography, 30, 3-12.
Travassos, L. (1937). Revisão da família Trichostrongylidea Leiper 1912. Memorias do Instituto Oswaldo Cruz, 1, 1-512.

Vicente, J. J., Rodrigues, H. D. O., Gomes, D. C., \& Pinto, R. M. (1997). Nematoides do Brasil. Parte V: Nematoides de mamíferos. Revista Brasileria de Zoologia, 14, 1-452.

Vidal-Martínez, V. M., \& Wunderlich, A. C. (2017). Parasites as bioindicators of environmental degradation in Latin America: A metaanalysis. Journal of Helminthology, 91, 165-173.

Whittaker, R. H. (1960). Vegetation of the Siskiyou Mountains, Oregon and California. Ecological Monographs, 30, 279-338.

Winegardner, A. K., Jones, B. K., Ng, I. S. Y., Siqueira, T., \& Cottenie, K. (2012). The terminology of metacommunity ecology. Trends in Ecology \& Evolution, 27, 253-254. 